This item was submitted to Loughborough's Research Repository by the author.

Items in Figshare are protected by copyright, with all rights reserved, unless otherwise indicated.

\title{
Incorporation of copper into indium gallium selenide layers from solution
}

PLEASE CITE THE PUBLISHED VERSION

PUBLISHER

(C) IEEE

VERSION

VoR (Version of Record)

LICENCE

CC BY-NC-ND 4.0

REPOSITORY RECORD

Hibberd, Christopher J., J. Ganchev, M. Kaelin, K.E. Ernits, and A.N. Tiwari. 2019. "Incorporation of Copper into Indium Gallium Selenide Layers from Solution”. figshare. https://hdl.handle.net/2134/4892. 
This item was submitted to Loughborough's Institutional Repository (https://dspace.lboro.ac.uk/) by the author and is made available under the following Creative Commons Licence conditions.

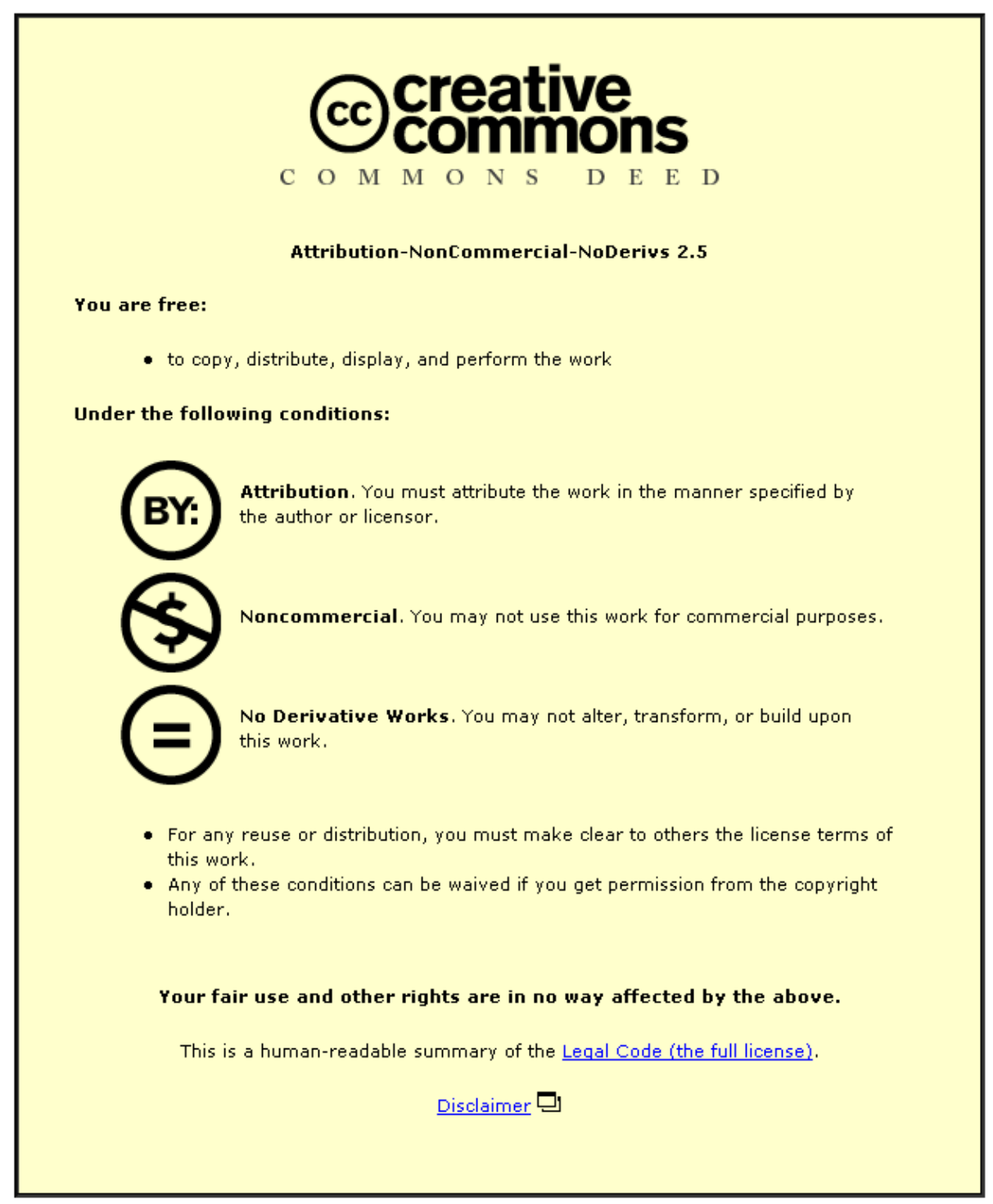

For the full text of this licence, please go to: http://creativecommons.org/licenses/by-nc-nd/2.5/ 


\title{
INCORPORATION OF COPPER INTO INDIUM GALLIUM SELENIDE LAYERS FROM SOLUTION
}

\author{
C. J. Hibberd ${ }^{1 *}$, M. Ganchev ${ }^{2}$, M. Kaelin ${ }^{3}$, K. Ernits ${ }^{4}$, A. N. Tiwari ${ }^{1,3}$ \\ 1)Centre for Renewable Energy Systems Technology, Holywell Park GX Area, Department for Electronic and Electrical \\ Engineering, Loughborough University, Leicestershire, LE11 3TU, UK
}

2) Central Laboratory of Solar Energy and New Energy Sources, Bulgarian Academy of Sciences, 72 Tzarigradsko

Chaussee, 1784 Sofia, Bulgaria

3) Thin Film Physics Group, Laboratory for Solid State Physics, ETH Zurich, Technopark, 8005 Zurich, Switzerland

4)Chair of Semiconductor Materials Technology, Department of Material Science, Tallinn University of Technology, Tallinn

19086, Estonia

*Corresponding author: C.J.Hibberd@Iboro.ac.uk

\begin{abstract}
A chemical method for the incorporation of copper into indium gallium selenide (IGS) layers has been developed. The resulting copper-containing precursor layers have been annealed in the presence of selenium vapour with the goal of forming $\mathrm{Cu}(\mathrm{In}, \mathrm{Ga}) \mathrm{Se}_{2}$ (CIGS) layers. It is found that copper ions in solution are incorporated into IGS layers during immersion, resulting in the formation of a precursor layer containing both copper selenides and IGS. When aqueous solutions are used for this process, corrosion of the molybdenum back contact occurs by reduction of copper ions in the solution. Use of an ethylene glycol solution prevents corrosion of the Mo and allows higher process temperatures, corresponding to higher reaction rates. During annealing, the precursor layers are converted into CIGS and the morphology of these layers is strongly affected by the availability of selenium whilst the substrate temperature is ramped up.
\end{abstract}

\section{INTRODUCTION}

The highest efficiencies reported to date for thin-film solar cells have been for devices based on $\mathrm{Cu}(\mathrm{In}, \mathrm{Ga}) \mathrm{Se}_{2}$ (CIGS) absorber layers $[1,2]$. These CIGS layers are deposited using expensive, high-vacuum equipment and it is expected that reductions in the cost of CIGS-based photovoltaics (PV) could be achieved by moving to simpler, non-vacuum based deposition techniques. Many such techniques have been investigated [3] and we have previously reported the use of an ion-exchange reaction as a step in the formation of a precursor layer suitable for conversion into $\mathrm{CulnSe}_{2}$ (CIS) [4]. Similar reactions have been applied to other thin-film PV applications, including formation of $\mathrm{Cu}_{2} \mathrm{~S}-\mathrm{CdS}$ structures, $\ln _{2} \mathrm{~S}_{3}$ and $\mathrm{CulnS}_{2}$ [5-7]. lon-exchange reactions are attractive from an industrial point of view as they require only simple, low-cost equipment, require relatively low temperatures compared to vacuum deposition, proceed at high rates and, unlike chemical bath deposition, allow extensive re-use of the reaction solutions.

In this work we report the advantages of using organic solutions over aqueous solutions for incorporating copper into IGS layers on molybdenum coated glass substrates and present the results of investigation into the chemicalphase and morphological transformations these layers undergo during conversion into CIGS.

\section{EXPERIMENTAL}

The copper incorporation process was performed on IGS layers deposited onto molybdenum-coated soda lime glass substrates. The Mo was deposited by DC sputtering and the IGS layers were deposited by co-evaporation of the elements. The In and $\mathrm{Ga}$ were evaporated from line sources and an excess of Se was provided from an effusion cell, substrate temperature was maintained at $400^{\circ} \mathrm{C}$. Vacuum deposition was used to provide a high degree of control over the IGS layers, however it would be desirable in future work to use a non-vacuum technique to deposit these layers.

The incorporation of $\mathrm{Cu}$ into the IGS layers was performed in both aqueous and organic baths. The aqueous bath typically contained $0.1 \mathrm{M} \mathrm{CuSO}_{4}$ and $0.2 \mathrm{M}$ acetic acid (to prevent hydrolysis of the $\mathrm{Cu}^{2+}$ ) whilst the organic bath typically contained $0.6 \mathrm{M} \mathrm{CuCl}$ and $1 \mathrm{M} \mathrm{NaCl}$ as complexant.

The precursor layers were annealed in a two temperaturezone quartz tube furnace under flowing $\mathrm{N}_{2}$ in order to investigate their conversion to CIGS, similar furnaces with both open and closed designs have been reported by previous authors [8, 9]. Se was supplied from a removable quartz crucible that was heated separately from the substrates to allow control of the Se supply during annealing. The heating rate of this system was limited to $\approx 50^{\circ} \mathrm{C} / \mathrm{min}$. 
Secondary electron images were recorded on a fieldemission gun Scanning Electron Microscope (SEM) at $5 \mathrm{keV}$ acceleration voltage whilst EDX measurements were performed on a tungsten filament SEM at $20 \mathrm{keV}$. Unpolarised micro-Raman spectroscopy measurements were performed using a He-Ne laser $(\lambda=632.817 \mathrm{~nm})$ with $\times 10$ objective lens. Electrochemical open-circuit potential measurements were recorded in an unstirred cell with a $\mathrm{Ag} / \mathrm{AgCl}$ reference electrode $(+0.222 \mathrm{~V}$ vs $\mathrm{NHE})$ in a side arm connected to the cell by a Luggin probe.

\section{RESULTS AND DISCUSSION}

\section{Chemical incorporation of $\mathrm{Cu}$}

When $\ln _{2} \mathrm{Se}_{3}$ layers were immersed in hot, aqueous, acidic copper sulphate solution it was found that copper was incorporated into the layers as $\mathrm{Cu}_{2} \mathrm{Se}$ [4]. The composition of a set of such layers as measured by EDX before and after annealing with Se vapour is shown in Fig. 1A. The composition measurements of the precursor layers before annealing are provided for comparison only. Due to the compositional gradient present in the layers exact quantification is not possible with EDX. The measured compositions lie close to the $\ln _{2} \mathrm{Se}_{3}-\mathrm{Cu}_{2} \mathrm{Se}$ pseudo-binary tie-line, though offset to the Se-poor side. The selenium deficiency is more pronounced for very copper poor layers.

All of the layers represented in Fig. 1A were $700-800 \mathrm{nms}$ thick. To incorporate $\approx 21$ at. $\% \mathrm{Cu}$ into a layer of this thickness requires $\approx 60$ minutes in boiling aqueous solution. When converted to $\mathrm{CIS}$ by annealing in Se vapour, such layers were found to increase in thickness by $\approx 10 \%$. Such layers are still thinner than desired for use as absorbers in solar cells, however attempts to increase the thickness of the layers were hampered by the corrosion of the Mo back contact when exposed to the solution, which led to undercutting of the $\ln _{2} \mathrm{Se}_{3}$ layer.

To investigate the cause of the Mo corrosion, open circuit potential measurements were made on Mo films in solutions of acetic acid and in solutions of acetic acid with $\mathrm{CuSO}_{4}$. The evolution of the open circuit potential of these films with time is shown in Fig. 2. The potential in the copper-free solution indicates that the Mo layer is inert in dilute acetic acid whilst the open circuit potential in the copper solution indicates that $\mathrm{Cu}^{2+}$ is being reduced, most likely according to Equation 1, with the expected counterpart anodic reaction being the oxidation of Mo (Equation 2).

$$
\begin{array}{cc}
\mathrm{Cu}^{2+}+2 e^{-} \rightarrow \mathrm{Cu} & 0.11 \mathrm{~V} \text { vs } \mathrm{Ag} / \mathrm{AgCl} \\
\mathrm{Mo} \rightarrow \mathrm{Mo}^{3+}+3 e^{-} & -0.47 \mathrm{~V} \text { vs } \mathrm{Ag} / \mathrm{AgCl}
\end{array}
$$
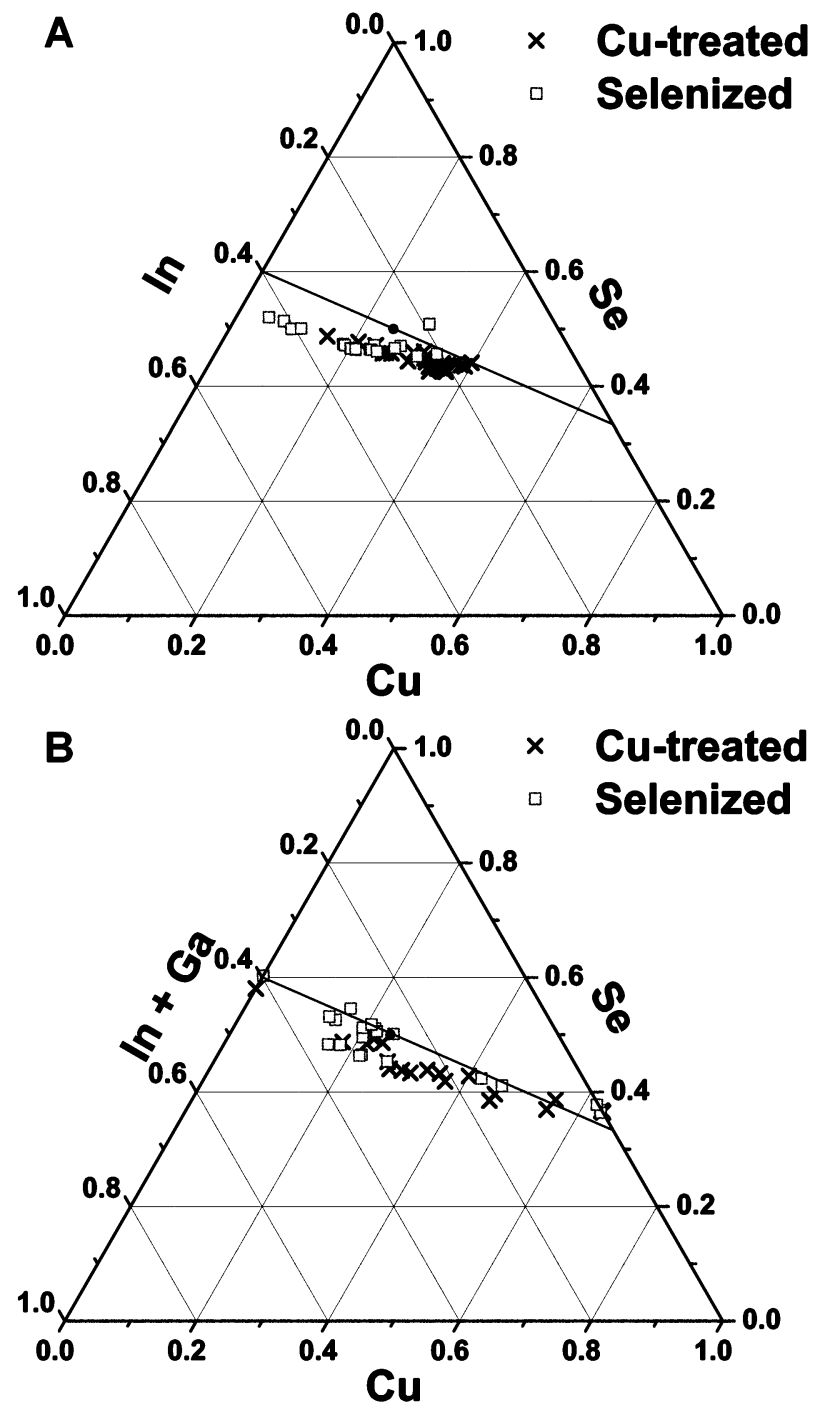

Fig. 1. Ternary composition diagrams for indium selenide layers treated in aqueous $\mathrm{CuSO}_{4}$ solution (A); and indium gallium selenide layers treated in organic $\mathrm{CuCl}$ solution (B). All samples represented here in the $\mathrm{Cu}$-treated data sets are also represented in the selenized data sets.

The destruction of Mo layers has previously been reported to occur in acidic $\mathrm{NaSO}_{4} / \mathrm{CuSO}_{4}$ solution by the same mechanism during investigation of electrochemical reactions involving $\mathrm{Cu}$, In and $\mathrm{Se}[10]$. Replacement of the Mo layer with other contact materials (FTO, ITO) resulted in no incorporation of $\mathrm{Cu}$ into the layers, which indicates that the reduction of $\mathrm{Cu}^{2+}$ by $\mathrm{Mo}$ is required to produce a source of $\mathrm{Cu}^{+}$ions for incorporation into the $\mathrm{In}_{2} \mathrm{Se}_{3}$ film. 




Fig. 2. Open circuit potential $\left(E^{0}\right)$ of Mo coated glass in 2 different electrolytes. That $E^{O}$ is close to zero in the acidic solution indicates that no corrosion is occurring. In $\mathrm{CuSO}_{4}$ solution $E^{0}$ is close to the value expected for the reduction of $\mathrm{Cu}^{2+}$ ions to $\mathrm{Cu}$.

Since $\mathrm{Cu}^{+}$salts are soluble in aqueous solutions only at very low $\mathrm{pH}$, alternative solvents were investigated. Ethylene glycol was found to be a very good solvent in which to perform the reaction as it is inexpensive, nontoxic and has a high boiling point $\left(\approx 196^{\circ} \mathrm{C}\right)$. After processing in ethylene glycol solution, no damage to the Mo layers was observed. When the composition of IGS layers was measured by EDX after immersion in ethylene glycol solutions containing $\mathrm{CuCl}$, it was found that $\mathrm{Cu}$ was incorporated into the IGS layers. The composition of a set of these layers before and after annealing is shown in Fig. 1B. Since the Mo back contact is stable in the ethylene glycol solution, thicker layers could be processed and the results presented in Fig. 1 are for 1.5-2 micron thick layers. Since the temperature and duration of the $\mathrm{Cu}$ treatment controls the quantity of $\mathrm{Cu}$ incorporated into the IGS layers, they can be processed in relatively very short times in the high-temperature solution, i.e. 40 minutes at $160^{\circ} \mathrm{C}$ for 21 at.\% Cu in a 2 micron thick IGS layer. Samples prepared at the extremes of the Cu-treatment (i.e. no copper treatment and treatment for sufficient time to completely convert the IGS layer) reveal terminal compositions corresponding to the compounds ( $I n_{1}$ $\left.{ }_{z} \mathrm{Ga}_{z}\right)_{2} \mathrm{Se}_{3}$ and $\mathrm{Cu}_{2-x} \mathrm{Se}$. The results presented in the following sections of this article are for IGS layers processed at $160^{\circ} \mathrm{C}$ in ethylene glycol solution containing $0.6 \mathrm{M} \mathrm{CuCl}$ and $1 \mathrm{M} \mathrm{NaCl}$.

Fig. $\quad 3 A$ and $B$ display SEM micrographs of the morphology and cross-section of as-deposited IGS and a $\mathrm{Cu}$-treated layer. The morphology of both layers is very similar, though the sharp edges visible on the surface of the IGS layer appear more rounded after Cu-treatment. In cross-section it is clear that no significant increase in layer thickness occurs during Cu-treatment, an observation that is supported by stylus profilometry measurements. The unchanged morphology and thickness are taken as strong evidence that the incorporation of $\mathrm{Cu}$ into the IGS layers occurs by an ion-exchange process. The change in contrast that is seen in the upper half of the Cu-treated layer cross-section micrograph is due to an increase in the electrical conductivity of this portion of the layer due to replacement of IGS by $\mathrm{Cu}_{2-x}$ Se phases at the surface. Increases in electrical conductivity have been confirmed by four-point-probe measurements.

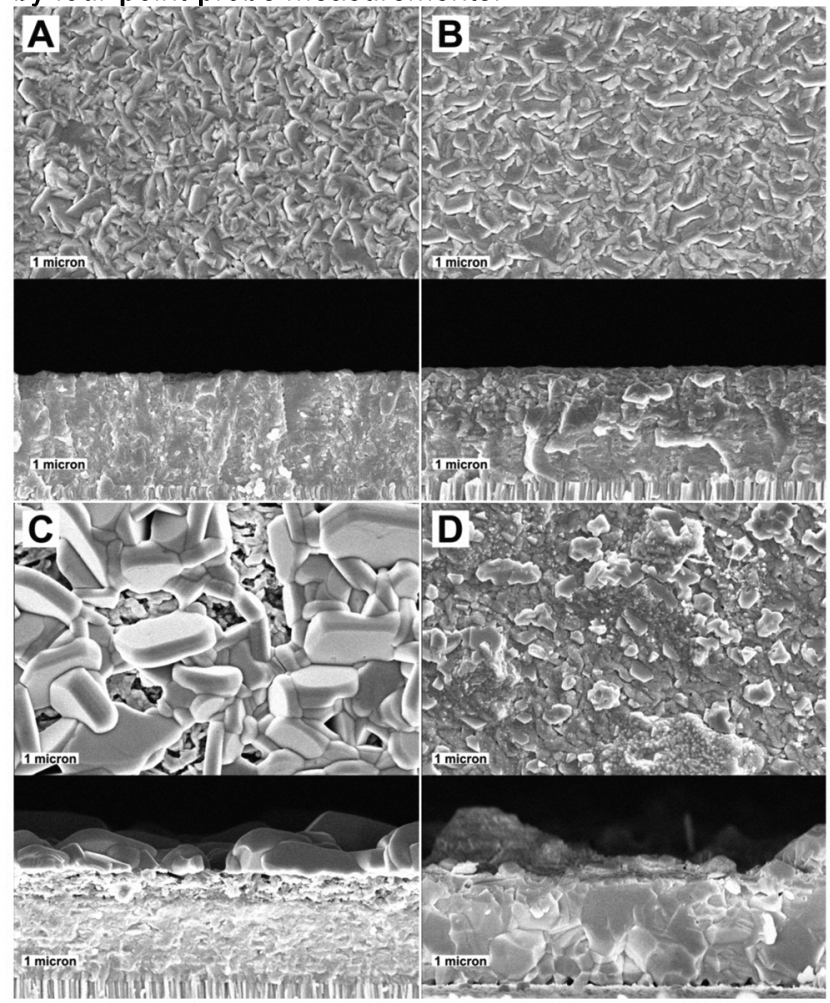

Fig. 3. Secondary electron images of as-deposited indium gallium selenide (A); Cu-treated indium gallium selenide (B); a precursor layer annealed at $250^{\circ} \mathrm{C}$ with Se vapour (C); and a precursor layer annealed at $575^{\circ} \mathrm{C}$ with $\mathrm{Se}$ vapour (D).

\section{Selenization of precursor layers}

Fig. $3 C$ and $D$ show SEM micrographs of CIGS layers formed by annealing precursor layers with the Se vapour source pre-heated before substrate heating commenced, ensuring a supply of Se vapour throughout the entire annealing process. The layer shown in $\mathrm{C}$ was annealed at $250^{\circ} \mathrm{C}$ whilst the layer shown in $\mathrm{D}$ was annealed at a maximum temperature of $575^{\circ} \mathrm{C}$. It is clear that a large volume expansion relative to the precursor occurs at a temperature below $250^{\circ} \mathrm{C}$, accompanied by a phase segregation at the surface of the layer. The segregated surface phase consists of copper selenides with the general formula $\mathrm{CuSe}_{y}(1 \leq y \leq 2)$, whilst the under layer contains the IGS. Similar surface grains have been observed by other groups and identified as $\mathrm{y}$-CuSe [11, 12]. X-ray diffraction and Raman spectroscopy measurements (not shown) confirm that the layer selenized at $575^{\circ} \mathrm{C}$ has recrystallised as CIGS, but with a very rough morphology as observed by SEM. 
$\mathrm{CuSe}_{y}$ compounds are only stable up to at most $377^{\circ} \mathrm{C}$ at which point they can undergo phase transitions by loss of Se, resulting in a reversal of the volume expansion observed at lower temperatures [13]. A decrease in volume would also be expected if the $\mathrm{CuSe}_{y}$ were to react with IGS to form CIGS. These large changes in volume are thought to be responsible for the rough surface morphology of the CIGS layers and possibly for the formation of voids within the layers. In order to investigate them further, precursor layers were annealed with Se vapour for 30 minutes at $\approx 280^{\circ} \mathrm{C}$ and $\approx 380^{\circ} \mathrm{C}$, SEM micrographs of these samples are shown in Fig. 4A and $\mathrm{B}$, respectively. At $280^{\circ} \mathrm{C}$ a distinct layer of $\mathrm{CuSe}_{y}$ can still be seen on the surface of the layer, though the boundary between the layers is less distinct than in Fig. 3C. By $380^{\circ} \mathrm{C}$ the distinct bi-layer structure is no longer apparent and the large $\mathrm{CuSe}_{y}$ grains have collapsed, leaving many small voids and high surface roughness.

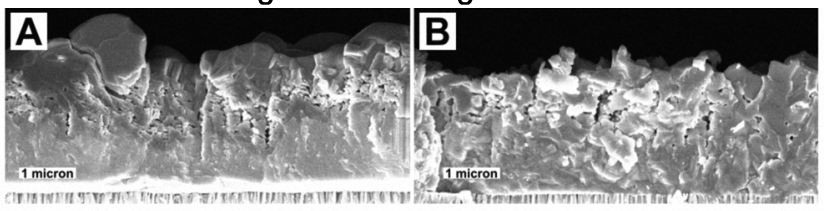

Fig. 4. SEM images of Cu-treated indium gallium selenide layers annealed with Se vapour at $\approx 280^{\circ} \mathrm{C}(\mathrm{A})$; and $\approx 380^{\circ} \mathrm{C}(\mathrm{B})$.

Raman spectroscopy measurements of these two films are displayed in Fig. 5. Due to the high absorption coefficients of copper selenides, the Raman signal is detected from just the top few hundred nanometres of the layers. As a result, only a peak corresponding to the $\mathrm{CuSe}_{y}$ compounds is detected for the sample annealed at $\approx 280^{\circ} \mathrm{C}$, whilst the spectrum for the sample annealed at $\approx 380^{\circ} \mathrm{C}$ exhibits two strong peaks, one characteristic of copper selenide compounds and one characteristic of CIGS $[14,15]$. This confirms that by $380^{\circ} \mathrm{C}$ the formation of CIGS has already begun and that the layer contains a mixture of binary and ternary/quaternary phases. During annealing these phases undergo structural and chemical phase transformations but the speed of these reactions is relatively slow at $380^{\circ} \mathrm{C}$, since not all of the copper selenide has been consumed after 30 minutes of annealing. Formation of CIGS whilst the layer is still so rough from the $\mathrm{CuSe}_{y}$ grain formation and collapse indicates that the morphology of the CIGS layers is strongly influenced at low temperatures during annealing.

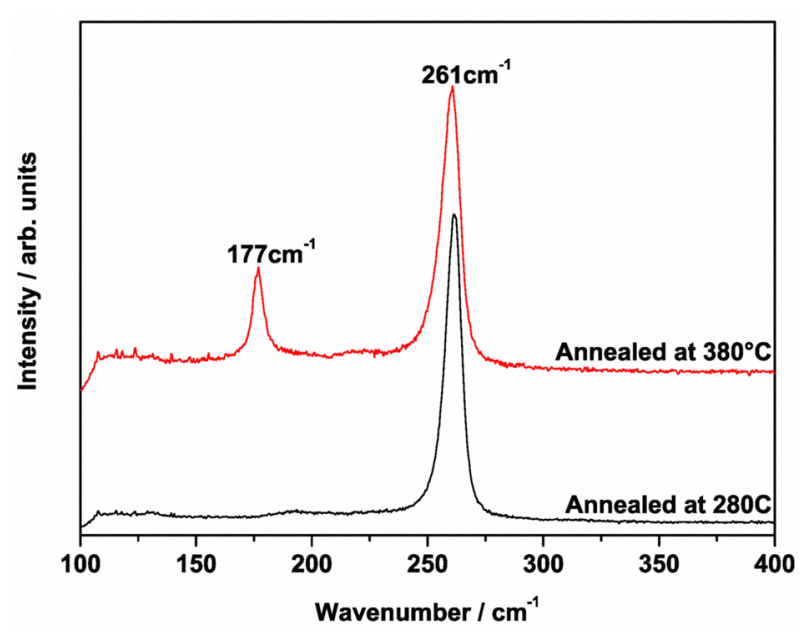

Fig. 5. Raman spectra for layers annealed at $\approx 280^{\circ} \mathrm{C}$ and $\approx 380^{\circ} \mathrm{C}$. The peak around $261 \mathrm{~cm}^{-1}$ is characteristic of copper selenide compounds and the peak at $177 \mathrm{~cm}^{-1}$ is associated with the $A 1$ vibrational mode of CIGS.

A rough interface is considered to be undesirable for CIGS layers to be used as absorber layers in PV devices for two reasons. Firstly, shunts through either the absorber or buffer layer are expected to occur more frequently than for smooth, compact absorber layers and secondly, interface area, hence device dark current density, increases with absorber surface roughness. To improve the smoothness of the CIGS layers, precursor layers were annealed at $250^{\circ} \mathrm{C}$ in the absence of Se vapour. Fig. 6A shows a SEM micrograph of such a layer and comparison with Fig. $3 B$ reveals no change in morphology with respect to the un-annealed Cu-treated layer. Fig. $6 \mathrm{~B}$ shows a secondary electron micrograph of a layer after annealing at $575^{\circ} \mathrm{C}$, in this case heating of the Se source did not begin until the substrate temperature reached $\approx 400^{\circ} \mathrm{C}$. It is seen that the layer has recrystallised homogeneously throughout its depth and has a very smooth surface. Whilst a large difference in grain size is observed between Fig. 3D and Fig. 6B, no conclusions should be drawn from this as dissimilar grain sizes have been observed in other samples that exhibit the same surface roughness dependence on Se supply. Understanding of the cause of these grain size differences requires further investigation.

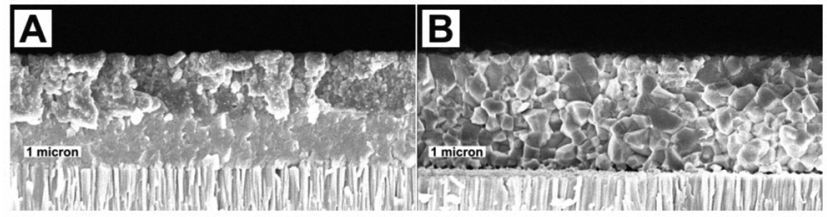

Fig. 6. Secondary electron images of layers annealed at $250^{\circ} \mathrm{C}$ in the absence of $\mathrm{Se}(\mathrm{A})$ and at $575^{\circ} \mathrm{C}$ with $\mathrm{Se}$ supplied once the substrate temperature was $\geq 400^{\circ} \mathrm{C}(\mathrm{B})$. The absence of $\mathrm{Se}$ at low temperatures prevents the formation of $\mathrm{CuSe}_{y}$ compounds and leads to smoother CIGS layers. 


\section{CONCLUSION}

$\mathrm{Cu}$ ion-exchange into indium gallium selenide layers is a potential step in the creation of a precursor for CIGS absorber layer formation by simple, low cost, non-vacuum methods. An improved solution in which to carry out this process has been identified to replace the aqueous solution used in our earlier work. This ethylene glycol solution of $\mathrm{CuCl}$ has the advantages of avoiding the corrosion of the Mo back contact and allowing higher temperatures, hence faster reaction rates, to be accessed. The precursor layers may be converted to CIGS by annealing and the supply of Se during the annealing has been investigated. These investigations show that the details of the Se supply during annealing have a huge impact not just on the chemical-phase transformations undergone by the layers during annealing but also on the morphology of the layers and the crystallisation of the CIGS grains. Further work is required to optimise the annealing process to produce CIGS layers for use in highefficiency solar cells.

\section{ACKNOWLEDGEMENTS}

The authors would like to acknowledge the assistance of Dr Alejandro Perez-Rodriguez of the University of Barcelona for discussion of Raman spectroscopy, FLISOM AG where Dr Marc Kaelin is currently employed and a partial support from the Swiss Federal Office of Energy.

\section{REFERENCES}

[1] I. Repins, M. Contreras A., B. Egass, C. DeHart, J. Scharf, C. Perkins L., B. To, R. Noufi, "19.9\%-efficient $\mathrm{ZnO} / \mathrm{CdS} / \mathrm{CulnGaSe2}$ Solar Cell with $81 \cdot 2 \%$ Fill Factor", Prog. Photovoltaics Res. Appl. 2008.

[2] M. Green A., K. Emery, Y. Hishikawa, W. Warta, "Solar cell efficiency tables (Version 31)", Progress in Prog. Photovoltaics Res. Appl. 2008; 16, 61.

[3] M. Kaelin, D. Rudmann, A. Tiwari N., "Low cost processing of CIGS thin film solar cells", Solar Energy $2004 ; 77,749-756$.

[4] C.J. Hibberd, K. Ernits, M. Kaelin, U. Muller, A.N. Tiwari, "Chemical incorporation of copper into indium selenide thin-films for processing of CulnSe $\mathrm{C}_{2}$ solar cells", To be published in Prog. Photovoltaics Res. Appl. 2008.

[5] F. Pfisterer, "The wet-topotaxial process of junction formation and surface treatments of $\mathrm{Cu}_{2} \mathrm{~S}-\mathrm{CdS}$ thin-film solar cells", Thin Solid Films 2003; 431-432, 470-476.

[6] J. Moller, C.-. Fischer, H.-. Muffler, R. Konenkamp, I. Kaiser, C. Kelch, M.C. Lux-Steiner, "A novel deposition technique for compound semiconductors on highly porous substrates: ILGAR", Thin Solid Films 2000; 361-362, 113117.

[7] L. Dloczik, M.C. Lux-Steiner, R. Koenenkamp, "Study on the preparation of structured CulnS $_{2}$ films by ion exchange processes", Thin Solid Films 2003; 431-432 131-134.

[8] M. Kaelin, D. Rudmann, F.V. Kurdesau, H. Zogg, T. Meyer, A.N. Tiwari, "Low-cost CIGS solar cells by paste coating and selenization", Thin Solid Films 2005; 480 481, 486.

[9] J.F. Guillemoles, P. Cowache, A. Lusson, K. Fezzaa, F. Boisivon, J. Vedel, D. Lincot, "One step electrodeposition of CulnSe2: Improved structural, electronic, and photovoltaic properties by annealing under high selenium pressure", J. Appl. Phys. 1996; 79, 7293-7302.

[10] O. Ramdani, E. Chassaing, B. Canava, P.-. Grand, O. Roussel, M. Lamirand, E. Rzepka, A. Etcheberry, J.-. Guillemoles, D. Lincot, O. Kerrec, "Electrochemical cementation phenomena on polycrystalline molybdenum thin films from $\mathrm{Cu}(\mathrm{I})-\ln (\mathrm{III})-\mathrm{Se}(\mathrm{IV})$ acidic solutions", $J$. Electrochem. Soc. 2007; 154, D383-D393.

[11] F. Adurodija O., J. Song, S. Kim D., S. Kwon H., S. Kim K., K. Yoon H., B. Ahn T., "Growth of CulnSe2 thin flms by high vapour Se treatment of co-sputtered Cu-In alloy in a graphite container", Thin Solid Films 1999; 338, 13-19.

[12] F. Hergert, S. Jost, R. Hock, M. Purwins, "A crystallographic description of experimentally identified formation reactions of $\mathrm{Cu}(\mathrm{In}, \mathrm{Ga}) \mathrm{Se} 2 "$, J. Solid State Chem. 2006; 179, 2394-2415.

[13] T.B. Massalski, J.L. Murray, L.H. Bennett and H. Baker, Binary alloy phase diagrams, 1, 1986, Ohio.

[14] V. Izquierdo-Roca, A. Perez-Rodriguez, A. RomanoRodriguez, J.R. Morante, J. Alvarez-Garcia, L. CalvoBarrio, "Raman microprobe characterization of electrodeposited S-rich Culn(S,Se $)_{2}$ for photovoltaic applications: Microstructural analysis", J. Appl. Phys. 2007; 101, 103517-1-103517-8.

[15] X. Chuan-Ming, S. Yun, L. Feng-Yan, Z. Li, X. YuMing, H. Qing, L. Hong-Tu, "Composition-induced structural modifications in the quaternary Culn ${ }_{1-x} \mathrm{Ga}_{x} \mathrm{Se}_{2}$ thin films: bond properties versus Ga content", Chin. Phys. 2007 ; 16, 788-794. 